\title{
Un resto de latinidade en djudezmo, sardo e galego: a construcción verbal paraperifrástica Querer + participio
}

\author{
Xosé-Henrique COSTAS GONZÁLEZ \\ Universidade de Vigo \\ xcostas@uvigo.es
}

\begin{abstract}
RESUMO
No galego falado no suroeste de Galicia existe un tipo de construción verbal que coincide plenamente cunha construción idéntica en sardo e en djudezmo ou xudeu-español dos Balcáns. Nesta contribución pretendemos analizar esta conexión non casual entre galego e sardo e esbozamos a idea dunha orixe común nun tipo de construción latina da que só quedan hoxe resultados precisamente nas dúas linguas latinas máis arcaizantes: galego e sardo. E tamén pretendemos analizar se este tipo de construción verbal é perífrasis verbal ou non.
\end{abstract}

Palabras chave: galego, sardo, djudezmo, perífrasis, construción verbal.

[Recibido, abril 2014; aprobado, enero 2015]

A rest of latinidade in Djudezmo, Sardinian and Galician: the verbal construction paraperifrástica

Querer + participio

\begin{abstract}
In the Galician language spoken in the southwest of Galicia there is a type of verbal construction that fully coincides with an identical construction in Sardinian language and in Djudezmo, or JewishSpanish from the Balkans. In this contribution, we intend to analyse this not causal connection between Galician and Sardinian, and we suggest the idea of a common origin in a type of Latin construction which only remains precisely in the two Romance languages that are more fond of archaisms: Galician and Sardinian. We also analyse whether this type of verbal construction is a verbal periphrasis or not.
\end{abstract}

Keywords: Galician, Sardinian, Djudezmo, periphrasis, verbal construction. 
1. Neste artigo pretendemos analizar a construción verbal Querer + participio flexivo que presentan o xudeu-español dos Baláns, o sardo e algún dialecto galego, porque, segundo os contextos, dá toda a impresión de adoptar un comportamento perifrástico modal obligativo de participio. Estamos a falar da construción verbal formada polo presente ou o imperfecto de indicativo do verbo querer (quere, queren, quería, querían) máis un participio flexivo concordante en xénero e número co complemento directo $(\mathrm{CD})$ ou co suxeito da oración, construción esta que ten un valor obrigativo ou precisativo.

Esta construción verbal rexistrámola en galego nos seus dialectos suroccidentales ou tudenses, pero en absoluto é microdialectal porque tamén existe identicamente noutras linguas e variedades románicas como o sardo ou o djudezmo dos Balcáns; de aí a nosa sospeita de que se trata dunha locución panromânica de orixe latina non exclusiva do galego, ainda que conservada no domínio galego nunha pequena área da marxe suroccidental.

A práctica totalidade dos falantes das variedades do galego suroccidental (coincidentes co territorio da diocese de Tui ou da antiga demarcación chamada Terra de Turonio) teñen na súa fala esta construción verbal, da que non achamos rastro no galego común nin en ningunha outra lingua iberorrománica, a non ser, como galeguismo evidente, no castelán hoxe falado precisamente nesta comarca suroccidental galega.

No galego, a primeira aproximación ao estudo desta construción fíxoa o profesor Delio García Represas (2001) cando a tratou como unha das maneiras de expresar unha necesidade en galego, unha maneira «que non determina ou Experimentador dá necesidade, pois ou Suxeito é asemade Experimentador, Paciente potencial dá acción».

Estamos a referirnos a enunciados como:

(1) estes nenos querían bañados e deitados

equivalente a

estes nenos habería que bañalos e deitalos

a estes nenos deberían bañalos e deitalos estes nenos deberían ser/estar bañados e deitados estes nenos tingan que ser/estar bañados e deitados estes nenos tingan de ser/estar bañados e deitados estes nenos necesitan ser/estar bañados e deitados

García Represas (2001:97) di desta locución ou construción verbal tudense que:

\begin{abstract}
Resúltanos bastante malo de caracterizar sintácticamente esta construción: a súa aparente unidade funcional fíxonos pensar durante algún tempo que poderiamos estar diante dun complexo perifrástico, pero o feito de que non manifeste un comportamento en bloque na proba da transformación interrogativa levounos a desistir de tal consideración (...) descartada a interpretación perifrástica, teríase que cualificar a construción como de Complemento Directo, o que parece un pouco forte dada a concordancia que mantén o participio respecto do Suxeito.
\end{abstract}

Nas gramáticas e nos manuais gramaticales das linguas galega, portuguesa e española non hai nin sequera unha mínima referencia a este complexo verbal que, en ocasións, toma a aparencia dunha perífrasis ou parece querer funcionar como unha verdadeira perífrasis verbal de participio (PVP). Esa non aparición por ningún lado moi probablemente sexa deba á súa ausencia dos textos e á súa circunscrición oral microdialectal ao territorio do suroeste pontevedrês ou tudense. 
Normalmente son cinco as construcións perifrásticas modais obligativas que aparecen en todas as gramáticas e manuais da lingua galega:

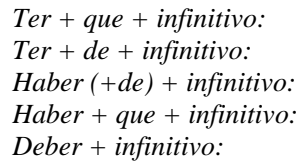

Tesme que recomendar un roteiro pola túa terra Tes de vir antes dás nove se queres que che levemos Has de facer ou que che eu mande, non ou que eu faga Este vestido hai que ganduxalo ben antes de coselo Debes marchar cedo porque logo vai vir a chover

A construción querer + participio flexivo pode presentar ás veces algunha anomalía na interpretación semántica da construción fóra do territorio tudense. Por exemplo, se un falante común de galego, de portugués ou de español escoitase o enunciado este nenos queren comidos probablemente quedaría totalmente estrañado, pois entendería algo así como hai que comer a estes nenos, é preciso comer a estes nenos, e non o sentido orixinal que lle pretende dar o emisor da mensaxe: a estes nenos hai que darlles para comer / estes nenos necesitan comer / estes nenos merecen comer, e non co matiz «antropofáxico» que entendería un falante común.

Así mesmo, podemos achar tamén unha anomalía nun significante -xa detectada tamén por Represas-, cando o participio de matar é substituído polo de morrer en enunciados como eses violadores querían mortos, co significado inequívoco de: é preciso matar a eses violadores / eses violadores merecen que os maten / hai que matar a eses violadores / é necesario matar a eses violadores etc. Fóra destas dúas anomalías, o seu funcionamento é regular.

2. A nosa sorpresa vén dada cando comprobamos a existencia dunha construción verbal idéntica, formal e conceptualmente, en sardo e en djudezmo ou xudeu-español dos Balcáns:

En sardo o enunciado:

(2) sos pabiros cherent presentados curmá de sa chenàpura chi benit

ten o seu equivalente exacto no galego suroccidental como

(2a) os papeis queren presentados antes do vindeiro venres

mientres que os seus equivalentes en galego común serían:

os papeis hai que presentalos antes do vindeiro venres

os papeis débense presentar antes do vindeiro venres

os papeis deben ser/estar presentados antes do vindeiro venres

os papeis teñen de/que ser/estar presentados antes do vindeiro venres

os papeis necesitan ser/estar presentados antes do vindeiro venres

E mesmo o uso anómalo do participio de morrer en lugar do de matar tamén existe en sardo. Así, unha secuencia en sarda como

(3) sos terroristas cherent mortos

é idéntica en galego suroccidental

(3a) os terroristas queren mortos 
que ten o seu equivalente en galego común

os terroristas merecen estar mortos

aos terroristas hai que matalos

En judezmo dos Balcáns o enunciado

(4) estes livros se keren maldados prima de amañana

ten o seu equivalente exacto en galego suroccidental

(4a) estes libros queren lidos antes de mañá

e estes serían os seus equivalentes en galego común:

\author{
estes libros hai que lelos antes de mañá \\ estes libros débense ler antes de mañá \\ estes libros deben ser/estar lidos antes de mañá \\ estes libros teñen de/que ser/estar lidos antes de mañá \\ estes libros necesitan ser/estar lidos antes e mañá
}

3. Nesta contribución queremos reflexionar sobre esta estructural verbal pode ser ou non (en ocasións, non sempre) unha verdadeira perífrase verbal, e para iso estudaremos o seu grao de cohesión gramatical, para que, no caso de que ás veces fose unha perífrase ou simplemente unha semiperífrase, non continúe ignorada por máis tempo nas gramáticas galegas.

Delio G. Represas, despois dun período de dúbidas e mesmo de consideración desta construción como perífrase, chegou á conclusión de que non pode ser perífrase verbal por non resistir a proba da transformación interrogativa, pero, como veremos máis adiante, hai outras probas de «pureza perifrástica», sobre todo de construcións verbais perifrásticas de participio, que si as supera. Non está totalmente gramaticalizada pero si presenta índices de gramaticalización e cohesión que tampouco podemos descartar sen máis. Adiantamos que en ocasións poderiamos estar a falar dunha perífrase, todo dependerá dos criterios empregados para a aceptación do título de perífrase ou de -simplemente- construción verbal singular.

Diciamos antes o da minusvalorización social desta construción porque os nosos informantes confirmáronnos plenamente o que nós xa viñeramos enxergando no noso ámbito familiar e social: que esta estrutura verbal é moi habitual na fala dos avós, é normal na fala dos pais, pero xa é esporádica ou inexistente na fala dos fillos, isto é: vai perdendo forza, vixencia e presenza, leva camiño da desaparición, por máis que as xeracións máis novas a recoñezan como familiar. Por iso esta construción cando menos semiperifrástica panrománica (posiblemente unha reliquia panrománica) merece ser analizada (quere analizada) e ten que ser valorada (quere valorada) novamente, pero sobre todo é necesario usala (quere usada) para que non desapareza.

4. Se esta construción verbal existe actualmente polo menos en galego, sardo e djudezmo, quizais sería posible que tivese orixes latinas comúns, polo que o primeiro que faremos será 
investigar por se nos latíns clásico, tardío e vulgar achamos restos, indicios ou ronseis desta estrutura.

Por unha banda, xa no latín tardío existía unha construción verbal formada por Uolo + infinitivo con valor de futuro, que nalgúns casos consolidouse plenamente como perífrase ao carecer de connotacións que recollesen o valor orixinario de uolo. Isto é: con uolo (e con querere) era posible formar perífrases en latín.

Por outra banda, a construción perifrástica pasiva do latín clásico: delenda est Carthago, («Cartago ten que ser destruída») tiña unha función obrigativa semellante ao que hoxe teñen o sardo e o galego tudense na locución obxecto de análixe: Cartago cheret destruia e Cartago quere destruída resprectivamente. Esta construción perifrástica pasiva foi perdendo o valor de deber no latín tardio e pasou a equivaler a «Cartago vai ser destruída», o que leva a pensar que para desempeñar esa función e significado primitivos a língua debeu de crear outras perífrases.

Por último, dentro do propio latín clásico, sería posible en principio que se combinasen un par de posibilidades gramaticales teoricamente existentes sobre as que se podería orixinar a nosa construción supostamente perifrástica querer + participio flexivo. $\mathrm{O}$ verbo uolo en latín clásico podía rexer infinitivo; o infinitivo pasivo perfecto en principio era amatum/amata esse, pero na práctica adoitaba abreviarse como amatum/amata, coa forma do participio, sen máis. Este infinitivo perfecto pasivo acabou sendo no latín tardío un infinitivo presente pasivo, como podería ser perfectamente -en frase inventada-, puella amata (esse) volebat, equivalente en galego á rapaza quería (ser) amada, a rapaza mercería (ser) amada > a rapaza quería amada.

Como podemos ver, achamos xa no propio no latín as posibles factores orixinarios desta locución que, todos xuntos, poderían orixinar sen dificultades unha construción verbal como a xa enunciada (puella amata (esse) volebat > puella amata volebat) xa que os mecanismos comúns da lingua permitirían perfectamente este tipo de formacións.

Só rexistramos un exemplo clásico dun caso semellante ao que nos ocupa: nun verso de Ovidio rexístrase unha construción con infinitivo pasivo que lembra bastante o xiro galego: vestis bona quaerit haberi, a boa roupa quere (ser) usada > a boa roupa quere usada (Amores I, 7, 51).

Se en latín serodio e vulgar eran posibles este tipo de construcións e existen na actualidade exemplos da súa vitalidade en lugares tan distantes como Sardeña e Galicia, o lóxico é pensarmos que nos achamos ante un constructo latino conservado precisamente nas dúas linguas románicas máis arcaizantes: sardo e galego (por esta orde). Agora ben, non detectamos ningún rexistro desta construción verbal en textos do galego antigo nin do galego medio, e tampouco a rexistramos en textos do galego moderno, en contraste coa grande vitalidade na fala popular do galego tudense.

O único exemplo escrito que coñecemos nunha lingua iberorrománica dunha construción semellante é unha frase dun texto en castelán da Inquisición redactado en Vigo no século XVI, concretamente en 1565, onde se atopa o enunciado «les llamaron una y muchas veces de judíos hijos de judíos y merecían quemados», en idéntico uso ao actual querían queimados, isto é: merecían ser queimados / había que queimalos / debían (de) ser queimados. Secasí, querer debeu ampliar o seu campo semántico de seres animados a seres inanimados desde o sentido de «querer» ao sentido de «merecer, precisar, necesitar», ata o extremo de facerse equivalente cos significados destes verbos e conmutable por eles; por iso é polo que tamén algún dester poderían aparecer en lugar de «querer», por exemplo nesta 
construción com particípio da que temos noticia desde hai medio milenio.

Afirma a este respecto Delio G. Represas (2001: 103):

Semella, logo, que nos atopamos en Querer + Participio cun excelente exemplo de gramaticalización histórica do tema (en suxeito) non noso romance, de xeito similar ó que se postula para a pasiva en estadios de lingua anteriores.

Querer «desexar» evolucionou semánticamente tamén a querer «precisar, necesitar, merecer». Para Represas esa pode ser un das orixes da construción, pero debemos lembrar de novo -e nós, ante a perspectiva panrománica optamos por esta vía-, que o infinitivo perfecto pasivo latino, amatum esse, adoitaba abreviarse formalmente como un simple participio, amatum, aínda que seguise tendo valor de infinitivo pasivo. É posible, por tanto, que nos achemos ante un resto ou pervivencia da construción latina de infinitivo pasivo abreviado fomalmente cunha forma semellante á do participio pero aínda con valor pasivo: parietes pictae (esse) volunt $=$ as paredes queren (ser/estar) pintadas $>$ as paredes queren ( $)$ pintadas.

As paredes queren $\varnothing$ pintadas

As paredes merecen ser/estar pintadas

As paredes necesitan ser/estar pintadas

As paredes deben ser/estar pintadas

5. Os autores que se ocuparon desta construción sempre dubidaron se a considerar perífrase ou non. A noción de perífrasis verbal e a clasificación de construcións verbais entre as perífrasis verbais é aínda na actualidade obxecto de análise e discusión. En palabras de Gómez Torrego, o concepto de «perífrasis verbal» é a historia dun longo proceso aínda inconcluso. No seu estudo sobre as perífrasis verbais, Gómez Torrego (1999:3325) defíneas como:

La unión de dos o más verbos que constituyen un solo «núcleo» del predicado. El primer verbo, llamado «auxiliar», aporta las informaciones morfológicas de número y persona y se conjuga en todas (o en parte de) las formas o tiempos de la conjugación. El segundo verbo, llamado «principal»o «auxiliar», debe aparecer en infinitivo, gerundio o participio, es decir, en una forma no personal. Según se trate de una u otra formas, hablamos de perífrasis verbales de infinitivo, de gerundio y de participio.

Con todo, aínda hoxe os gramáticos e lingüistas non se puxeron de acordo en moitos casos para distinguir entre o que é unha auténtica perífrase verbal e o que é unha simple construción na que hai un verbo conxugado máis un verboide (infinitivo, xerundio ou participio), porque entran en xogo criterios semánticos (o máis empregado é o da deslexicalización ou baleiramento léxico do auxiliar), criterios sintácticos e criterios morfológicos. O criterio de desemantización do auxiliar empregado de modo exclusivo, moi usado ata agora, non permite distinguir con claridade unha perífrase verbal de participio (PVP) de simples construcións non perifrásticas ou locucións con verbo desemantizado. A separación non é fácil.

Dentro do conxunto das perífrases verbais, as de participio son un caso aparte. A PVP expresa un significado complexo porque os dous elementos que a compoñen poden funcionar autónomamente noutros contextos, aínda que en uso perifrástico desempeñan indisolublemente una mesma unidade sintáctica e expresan o resultado previo ou simultáneo ao momento indicado polo auxiliar. Para que unha construción sexa perífrase verbal de 
participio (PVP), o verbo en forma persoal e o participio teñen que constituír un único núcleo verbal, non poden existir complementos que modifiquen exclusivamente o auxiliar e non toda a perífrase, e o participio ha de ter carácter verbal e non adxectival. Así, ten roto o brazo por dous sitios non é perífrase, pero ten roto o brazo varias veces nestes mes si o é.

Alarcos Llorach (1995:259) só considera verdadeiras PVP as formadas con haber + participio (os chamados tempos compostos), o resto di que son funcionalmente oracións con predicado nominal, mesmo a pasiva perifrástica con ser. Con todo, para Roca Pons (1958:10) poden existir PVP con 22 verbos auxiliares diferentes e con cinco verbos semiauxiliares, posto que para este autor hai perífrases e semiperífrases, en función do grao de cohesión gramatical que presenten os dous ou máis verbos que as conformen. Entre estes dous extremos hai toda unha gradación en canto á consideración do que son ou non son perífrases verbais de participio segundo os autores que as analicen.

\subsection{O problema da flexión do participio}

Hai unha característica da construción querer + participio que fai difícil que a maioría dos autores a poidan considerar perífrases en galego: a concordancia en xénero e número do participio co suxeito ou o CD da frase, isto é: o participio non está inmobilizado en masculino singular: as paredes queren pintadas / os nenos queren bañados / a parede quere pintada / o neno quere bañado. Como os participios levan trazos formais de concordancia co substantivo que fai de CD ou de suxeito, coma se fosen adxectivos, existe unha gran dificultade á hora de estableceren os diferentes autores as construcións verbais que poden funcionar verdadeiramente como perífrases.

Esta característica é problemática e discutida polos diferentes autores, porque polo menos nos tempos compostos (unha variedade consolidada de PVP) en moitas linguas románicas o participo concorda en xénero e número co suxeito ou o $\mathrm{CD}$ da oración. $\mathrm{E}$ moitas veces non é fácil xebrar entre participio e adxectivo. Como forma nominal, o participio ten flexión de xénero e número cando concorda co suxeito na voz pasiva e permanece ríxido no masculino singular en perífrasis ou complexos verbais.

Agora ben, nalgunhas poucas perífrases galegas admítese esta dobre posibilidade de emprego dun participio inmobilizado ou dun participio flexivo.

\section{Aínda non deu escritas as cartas = Aínda non deu escrito as cartas

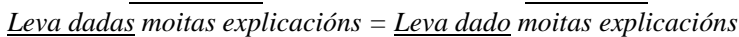

Álvarez e Xove, na súa Gramática da lingua galega (2002:336-337) manifestan verbo disto que a «ausencia de concordancia do participio caracteriza inequivocamente a perífrases, mais este non é un trazo obrigado, pois poden existir tamén perífrases cando o participio concorda co seu suxeito ou OD».

Lembremos tamén que nas perífrases baixolatinas e medievais que deron orixe aos tempos compostos nas diferentes linguas románicas, tamén os participios tiñan concordancia en xénero e número:

...pecunias magnas collocatas habent

...que sa irmãã era passada deste mundo...

.... razõ por isto avemosla ja dita...

...dereyturas que eu xa avia vendudas a...

Por tanto, a rixidez do participio non sería conditio sine qua non para que Querer + 
Participio (flexivo) puidese ser considerada como unha construción de uso total ou parcialmente perifrástico.
(5) As orixes disto
querían estudadas
habería que estudalas
con máis vagar
deberían ser/estar estudadas
terían que ser/estar estudadas
terían que estudalas
necesitarían ser/estar estudadas
queren presos
hai que prendelos
teñen que prendelos
teñen que estar presos
deberían de prendelos
deberían de estar presos
(6) Os violadores
merecen ser/estar presos
(7) Estas paredes queren pintadas
hai que pintalas
teñen que pintalas
teñen que estar pintadas
deben de pintalas
deben de estar pintadas
necesitan ser/estar pintadas
toda a vida
antes de que chegue o inverno

\subsection{Probas de autenticidade perifrástica nas PVP}

Segundo os autores que manexemos, variados serán os criterios establecidos para comprobar a autenticidade perifrástica dunha construción verbal. Cantos máis criterios cumpra, maior será a súa gramaticalización e cohesión, maior será a porcentaxe de posibilidades de considerala construción perifrástica de participio. Pero teñamos en conta que todos e cada un destes criterios non son infalibles e, así o recoñecen os diferentes autores, sempre poden existir excepcións a cada un dos criterios.

a) Se hai resposta á pregunta «como?» entón non hai PVP

Estaban contentas polas notas / Como estaban ? ? contentas

O neno quere bañado agora / Como quere ? ?

b) Se hai posibilidade de substituír o participio por un adxectivo, ou un adverbio, ou unha locución adverbial de CC., entón non hai PVP.

Leva posto o sombreiro na cabeza ? Leva (colocado) un sombreiro na cabeza.

$O$ neno quere bañado agora / O neno quere ? agora.

c) Se o participio se coordina cun adxectivo, non hai PVP

Tiña lavados e brancos os dentes

Os nenos querían bañados e quentes

d) Se se suprime o participio e non se altera o significado, non hai PVP

Van marcados catro goles $=$ Van catro goles $=$ Van catro goles marcados

A parede quere pintada $=/=$ A parede quere ?

Segundo Gómez Torrego, a superación destas catro probas expresa o grao de cohesión 
entre auxiliar e participio, a maior gramaticalización, porque o carácter perifrástico dunha construción verbal é un proceso gradual. A total gramaticalización dunha PVP só se dá nos chamados tempos compostos, onde se rexistra a perda de todo trazo formal adxectivo do participio, pero non existe esa gramaticalización absoluta, senón gradual, no resto de construcións verbais con participio.

A construción Querer + Participio non cumpre todos os criterios, só algúns, pero entón fai falla formular se poderían existir construcións de menor gramaticalización que presenten un comportamento perifrástico ou semiperifrástico segundo certos contextos favorables.

\subsection{Outras consideracións}

Este tipo de construción ou complexo verbal de Querer + Participio pode admitir a intercalación dun adverbio, polo que a locución adquire unha carga adxectival, dado que o adverbio modifica o adxectivo. Ponse de manifesto deste xeito que a suposta perífrase non está ancorada, estabilizada, polo que nestes casos achariámonos ante unha falsa perífrase aínda non consolidada como tal.

(8) Estas paredes queren máis pintadas (hai que as pintar máis)

Estas paredes queren moi pintadas (hai que as pintar moito)

Estas paredes queren mellor pintadas (hai que as pintar mellor)

Estas paredes queren pouco pintadas (hai que as pintar pouco)

Estas paredes queren ben pintadas (hai que as pintar ben)

Con todo, esta tendencia á imposibilidade de intercalación de elementos entre auxiliar e Participio non é completa nin siquera nos tempos compostos, que son considerados por todo o mundo como as auténticas, exemplares e paradigmáticas PVP. Gómez Torrego ilústranos cunha secuencia perfectamente posible en castelán:

(9) Nos habían siempre dicho que esto no ocurriría nunca

O que tamén é posible nesta construción que nos ocupa nos exemplos anteriores ou noutros como:

(9) O avó sempre quere ceado ás oito

O avó quere sempre ceado ás oito

O avó quere ceado sempre ás oito

Por tanto, este tipo de intercalaciones, que para algúns autores son imposibles nas PVP, vemos como para outros non só son posibles senón que non afectan maiormente á consideración de PVP.

Por último, debemos indicar que na construción que nos ocupa o verbo querer non sempre perde toda a súa carga semántica, ao poder significar merecer $(+$ ser/estar $)$, necesitar ( + ser/estar), como xa aparece expresamente no texto do s.XVI citado anteriormente.

$\mathrm{Na}$ oración este rapaz quere unha pouca de axuda, o verbo querer pode ser conmutado por merece/necesita/pide, ou tamén pola construción verbal (este rapaz) quere axudado con matiz de pasividade: merece ser / necesita ser / pide ser axudado.

O significado común de querer con todas estas formas continúa presente no complexo verbal obxecto de nosa análise, querer non se concreta sempre nun simple auxiliar, por iso é tan complicado atribuírlle o papel de verdadeira perífrase verbal. 
6. Para nós, xa que logo, trátase dunha construción verbal panrománica pre-, para- ou pseudo-perifrástica de obrigatoriedade e de necesidade, ou en todo caso dun complexo verbal aínda non consolidado sempre e totalmente como perífrase, unha «perífrasis» en potencia cun sutil matiz semántico que oscila entre a obrigatoriedade posterior e a recomendación necesaria posterior ou simple necesidade, segundo se use o auxiliar en presente de indicativo ou en imperfecto de indicativo (ou mesmo tamén en futuro hipotético).

\begin{tabular}{|l|l|l|}
\hline A meniña quere deitada & Obrigatoriedade, deber inminente & Hai que a deitar xa \\
\hline $\begin{array}{l}\text { A meniña quería / } \\
\text { querería deitada }\end{array}$ & $\begin{array}{l}\text { Recomendación, necesidade, suxestión, } \\
\text { invitación }\end{array}$ & $\begin{array}{l}\text { Conviría deitala, conviña deitala, } \\
\text { habería que deitala, alguén a } \\
\text { debería deitar, necesita que a } \\
\text { deiten, sería bo deitala... }\end{array}$ \\
\hline
\end{tabular}

Como vimos, non se trata dun endemismo micro-dialectal galego da Terra de Turonio ou tudense, senón que se trata na nosa opinión dun resto arcaico de latinidade ao existir con idéntico uso e significado noutras linguas e variedades románicas como o sardo ou o djudezmo e poder explicarse a partir do propio latín. E da mesma maneira que en sardo estándar normativo é habitual esta construción, estas e outras moitas mostras vivas dialectais do galego sería necesario incorporalas (querían incorporadas) ao galego común, conviría coñecelas e sería bo usalas (quererían coñecidas e usadas), aínda que só fosen microdialectalismos e houbese máis maneiras de expresar o mesmo. Son parte integrante do noso ADN lingüístico, románico e identitario e non debemos renunciar a elas.

\section{Bibliografía}

Alarcos Llorach, Emilio (1995): Gramática de la lengua española, Madrid: EspasaCalpe.

Álvarez Blanco, Rosario (1994): “Gramática descritiva e gramática prescritiva”. Cadernos de Lingua 10: 19-35.

Álvarez Blanco, Rosario /Xosé Xove Ferreiro (2002): Gramática da lingua galega. Vigo: Galaxia.

FERNÁNDEZ DE CASTRO, Félix (1990): Las perífrasis verbales en español. Comportamiento sintáctico e historia de su caracterización. Oviedo: Universidad de Oviedo.

FERNÁNDEZ DE CASTRO, Félix (1999): Las perífrasis verbales en el español actual. Madrid: Gredos.

FreiXeiro Mato, Xosé Ramón (2006): Gramática da lingua galega. II. Morfosintaxe. Vigo: A Nosa Terra.

GARCÍA REPRESAS, Delio (2001): “A necesidade e maila obriga en galego". Cadernos de Lingua 23: 85-116.

GÓMEz TORREGO, Leonardo (1999): "Las perífrasis verbales de infinitivo", en RAE: Gramática descriptiva de la lengua española, Vol. II Las construcciones sintácticas fundamentales. Relaciones temporales, aspectuales y modales, dirixida por Ignacio Bosque e Violeta Demonte. Madrid: Espasa Calpe, pp. 3323-3390.

Hermida GulíAs, Carme (2004): Gramática práctica (Morfosintaxe). Santiago de Compostela: Sotelo Blanco. 
LAMIROY, Beatrice (1991): Léxico y gramática del español: Estructuras verbales de espacio y tiempo. Barcelona: Anthropos.

López ViÑAs, Xoán/ Lourenço Módia, Cilha /Moreda LeIRAdo, Marisa (2010): Gramática práctica da lingua galega. A Coruña: Baía Edicións.

Moscoso MATO, Eduardo (2000): Os tempos compostos no galego medieval. Anexo 46 de Verba. Santiago de Compostela: USC.

RoCA PONS, José (1958): Estudios sobre las perífrasis verbales en español. Madrid: CSIC.

Rojo, Guillermo (1974): Perífrasis verbales en el gallego actual. Anexo 2 de Verba. Santiago de Compostela: USC.

YLleRA, Alicia (1980): Sintaxis histórica del verbo español: las perífrasis verbales. Zaragoza: Universidad de Zaragoza.

YLlERA, Alicia (1999): "Las perífrasis verbales de gerundio y participio", en RAE: Gramática descriptiva de la lengua española, Vol. II Las construcciones sintácticas fundamentales. Relaciones temporales, aspectuales y modales, dirixida por Ignacio Bosque e Violeta Demonte. Madrid: Espasa Calpe, pp. 3391-3442. 